\title{
Modification of the surface layers of copper by a diffuse discharge in atmospheric pressure air
}

\author{
Mikhail A. Shulepov ${ }^{1}$, Mikhail V. Erofeev ${ }^{1,2}$, Konstantin V. Oskomov ${ }^{1}$, Victor F. Tarasenko ${ }^{1,2^{*}}$ \\ ${ }^{1}$ Institute of High Current Electronics, SB, RAS, 634055, 2/3 Akademichesky Ave., Tomsk, Russia; \\ ${ }^{2}$ National Research Tomsk Polytechnic University, 634050, 30 Lenin Ave., Tomsk, Russia
}

\begin{abstract}
The paper presents the results of examination of copper samples exposed to a diffuse discharge initiated by a runaway electron beam in air under normal pressure. The changes in the chemical composition of the surface layers of copper caused by the action of the discharge were investigated. It has been found that the oxygen and carbon concentrations in the surface layers depend on the number of discharge pulses. The study was aimed at finding possible ways of using this type of discharge in research and industry.
\end{abstract}

Keywords: Runaway electrons preionized diffuse discharges, REP DD, surface modification, copper

\section{INTRODUCTION}

Studies on the surface modification of various materials by electrical discharges aimed at giving the materials new properties have been carried out for a long time, and quite a lot of meaningful results have been obtained in this area. As an example, we can cite the studies on nitriding of the surface of titanium [1] and on oxidation of iron and its alloys [2]. Deposition of various thin films on metal surfaces [3] can also be considered a surface modification technique. The relevant studies and the development of new methods of surface modification have the goal of generating new surface properties not typical of metals in the normal state. For example, nitriding of the surface of titanium not only changes the color of the metal, but also improves its wear resistance. An oxide film deposited on the surface of iron prevents penetration of atmospheric oxygen into the bulk metal, thereby protecting it from corrosion and destruction.

In recent years we have studied a new type of volumetric gas discharge, namely, the runaway electrons preionized diffuse discharge (REP DD) [4]. The distinguishing feature of this type of discharge is that it is volumetric at atmospheric and higher pressure of the working gas. The other feature is that the discharge does not require preionization of the gas for its initiation.

Progress in studying the properties of REP DDs gave us impetus to seeking their possible applications. Here we present the results of our investigations of the action of a diffuse discharge initiated by a runaway electron beam in air under normal pressure on copper.

\section{EXPERIMENTAL SETUP}

Experimental investigations of the REP DD action on various materials were carried out on a modernized setup based on a RADAN-220 generator, which produced voltage pulses of amplitude $\sim 360 \mathrm{kV}$ (open-circuit voltage), FWHM $\sim 0.7 \mathrm{~ns}$ (across a matched load), and rise time $\sim 0.5 \mathrm{~ns}$. Measurements have shown that the peak current was $\sim 3 \mathrm{kA}$ and the total discharge current pulse duration was $\sim 13 \mathrm{~ns}$ (the duration of the discharge current first half-period was $\sim 3 \mathrm{~ns}$ ) (Fig. 1). Irradiation of samples was performed in a repetitive pulse mode at a pulse repetition rate of $1 \mathrm{~Hz}$. A tube of diameter $6 \mathrm{~mm}$ made of titanium foil of thickness $50 \mu \mathrm{m}$ was used as a cathode and a plate of thickness about $200 \mu \mathrm{m}$ cut from specially prepared copper foil was used as an anode. The electrode gap spacing was $18 \mathrm{~mm}$. The experiment was carried out in an open chamber in atmospheric pressure air (Fig. 2).

The samples were prepared by polishing followed by rinsing with distilled water and alcohol in an ultrasonic bath. After wiping, a sample was placed in the discharge chamber where it was treated by a diffuse discharge operating in atmospheric pressure air (Fig. 3).

*VFT@1oi.hcei.tsc.ru; phone 83822 491-685; fax 83822 492-410; www.hcei.tsc.ru

International Conference on Atomic and Molecular Pulsed Lasers XII, edited by Victor F. Tarasenko,

Andrey M. Kabanov, Proc. of SPIE Vol. 9810, 98100Y · (c) 2015 SPIE

CCC code: $0277-786 \mathrm{X} / 15 / \$ 18 \cdot$ doi: $10.1117 / 12.2224926$

Proc. of SPIE Vol. $981098100 Y-1$ 
was used as a high voltage source [13]. With this generator, the specific power input to the discharge plasma was $\sim 10 \mathrm{MW} / \mathrm{cm}^{3}$. Plates of thickness $1 \mathrm{~mm}$ and foils of thickness $200 \mu \mathrm{m}$ were used for the anode. Irradiation was carried out in a repetitive pulse mode at a frequency of $2 \mathrm{kHz}$ in a stream of nitrogen or argon at a flow rate of $5 \mathrm{sl} / \mathrm{min}$.

In this experiment, an evacuated chamber was used through which the gas required for a particular experiment was pumped. In all cases, the gas pressure corresponded to the atmospheric pressure. Each sample was prepared by polishing followed by rinsing with distilled water and alcohol in an ultrasonic bath. After wiping, the sample was placed in the discharge chamber where it was treated with a diffuse discharge (Fig. 1).

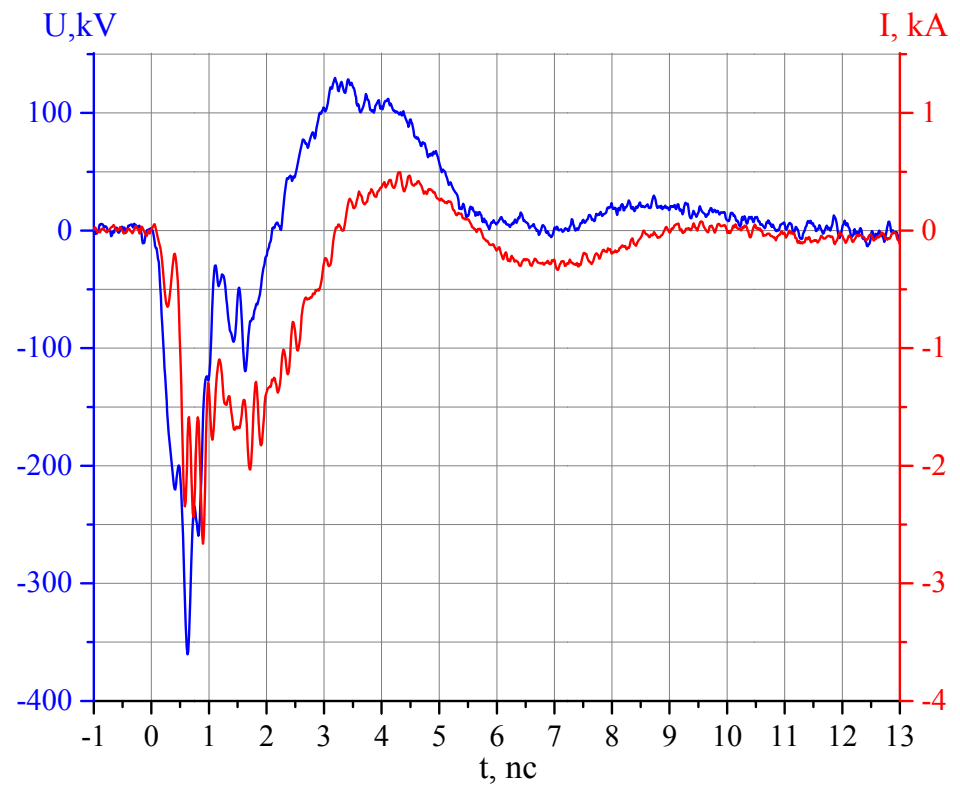

Figure 1. Oscilloscope traces of applied voltage pulse and discharge current.

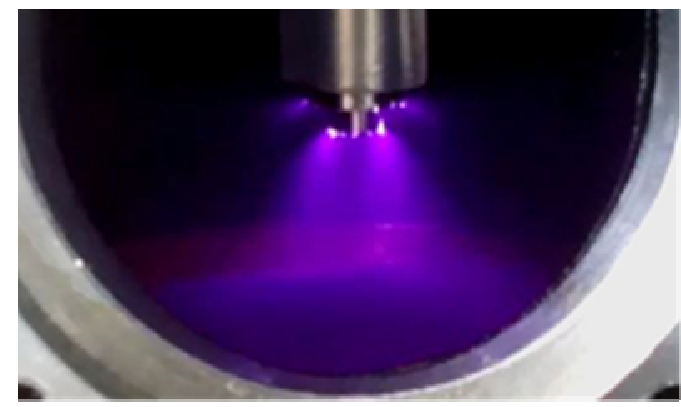

Figure 2. Photograph of the volume discharge from the side view.
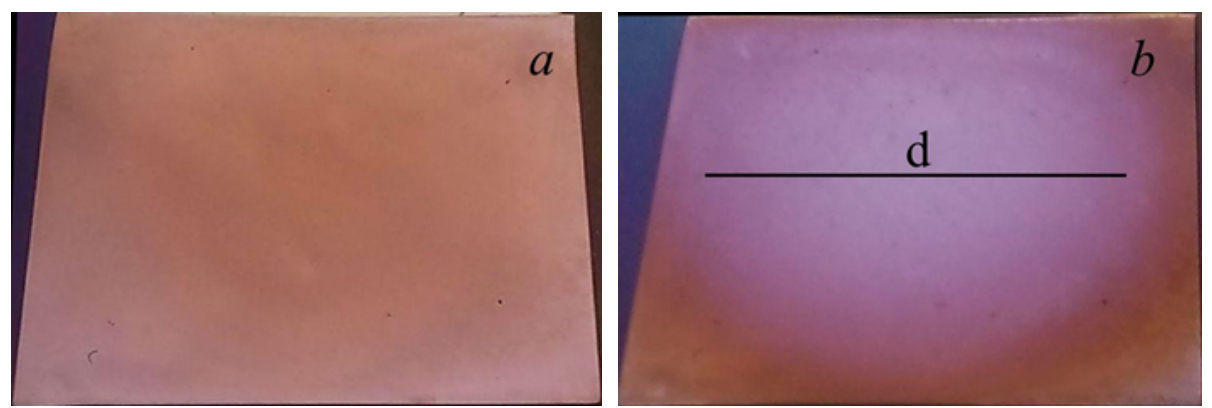

Figure 3. A copper sample before (a) and after exposure to 6600 discharge pulses (b). 


\section{RESULTS AND DISCUSSION}

While exposed to the discharge, the sample surface first darkened to dark red, and after 1500 pulses, it began to brighten to white with a blue tint. In total, the sample was exposed to 6600 discharge pulses.

In the course of the experiment it was observed that when the setup was operated with the discharge chamber open, some nitrogenous compounds and compounds containing an $\mathrm{OH}$ group were produced along with ozone [5].

After discharge treatment, the samples were placed, to prevent the influence of air, in a capsule filled with an inert gas (argon) and passed for Auger spectroscopy to examine the elemental composition of their surface layers. The examination was performed with the use of a Shtil-2 Auger spectrometer [6].

The data on the chemical composition of the sample surface layers are presented in Fig. 4.
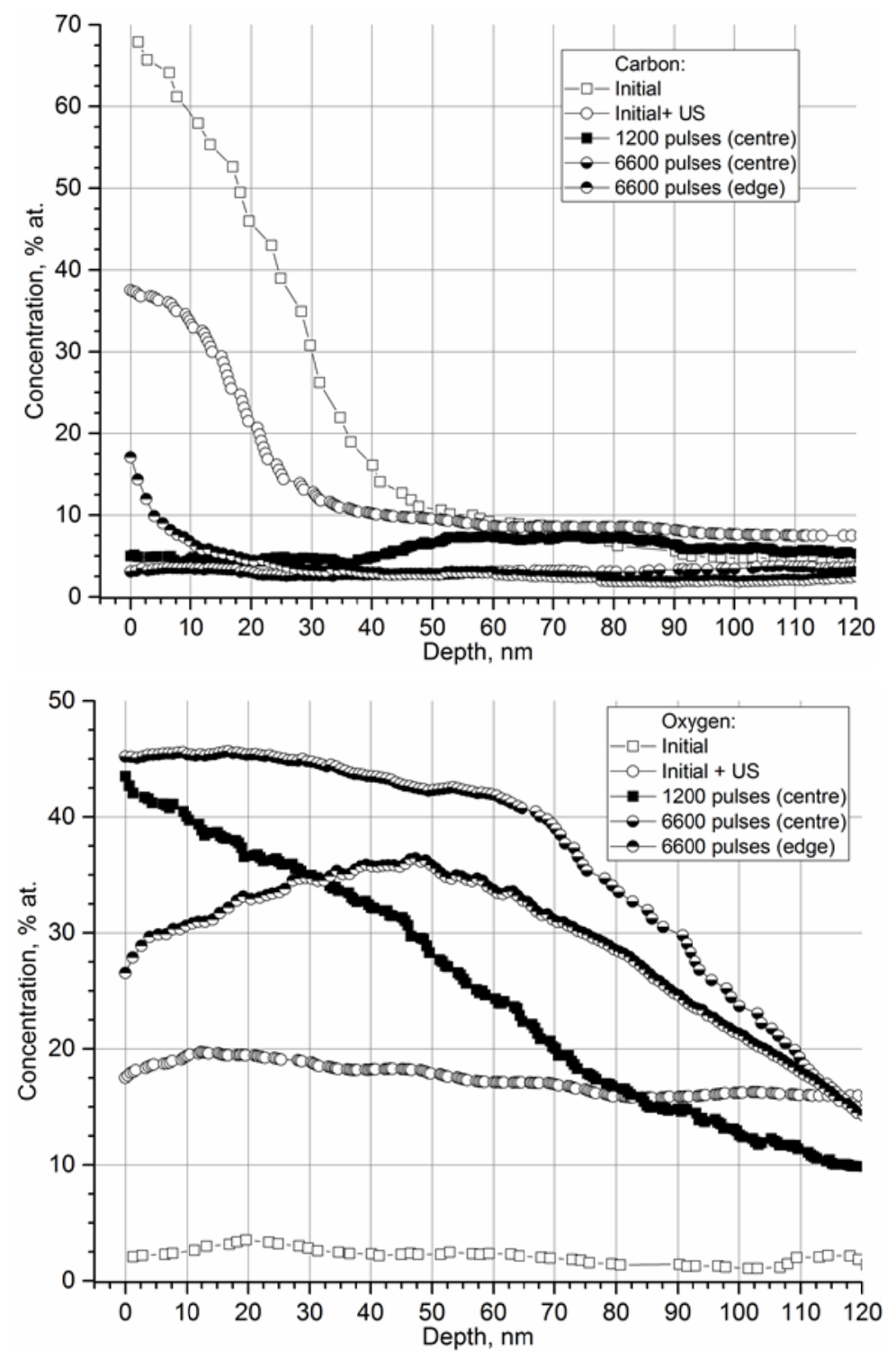

Figure 4. Carbon and oxygen concentrations in the surface layers of copper.

As can be seen from the plots of Fig. 4, the surface layers of the as-polished sample contain carbon in significant amounts (about $70 \%$ at.) and oxygen in small amounts, within measurement error (about $5 \%$ for the method used). The carbon is present, most likely, as hydrocarbon compounds (the method cannot detect hydrogen). The small oxygen 
content in the as-prepared samples allows us to be confident that the samples were well protected during inter-test periods and the cleaned metal surface was only slightly influenced by the atmospheric air.

Rinsing the sample in an ultrasonic bath reduced the concentration of hydrocarbons in the surface layers, as evidenced by a decrease in carbon concentration, but significantly increased the concentration of oxygen (by up to $18 \%$ at.) for a considerable depth $(300 \mathrm{~nm})$.

The discharge treatment of copper additionally removed carbon-containing compounds from the surface, but made it even more oxidized. It should be noted that the oxygen content in the surface layers significantly depended on the irradiation dose and on that whether the surface was directly exposed to the discharge. This follows from the difference in oxygen concentration between the central region of diameter $\sim 2.5 \mathrm{~cm}$ (see Fig. $3 \mathrm{~b}$ ) and the edge of the sample exposed to the discharge.

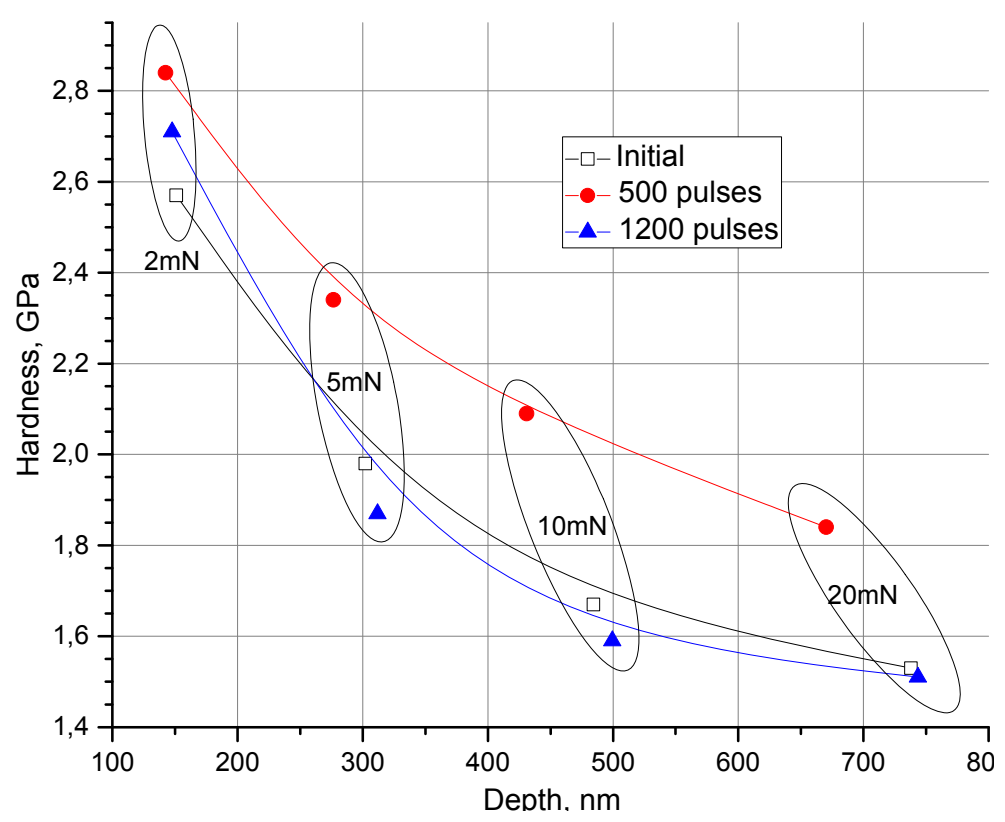

Figure 5. Nanohardness changes in niobium versus load and depth.

Study of the hardness of the treated copper samples shows (see Fig. 5) that its hardrness slightly increased after discharge treatment, then began to decreased with the increasing of the exposure dose. Apparently, products, which was formed on the copper surface in the plasma chemical reactions, have more porous structure than the initial samples. This theory will be checked in further experiments on structural study of the samples.

\section{CONCLUSIONS}

The oxidation of copper in the atmospheric air is a self-extinguishing process, as the growing oxide film prevents oxygen from penetration into the metal bulk, and goes through two stages. The first stage is the formation of a primary film consisting of a mixture of oxides and pure dicopper oxide. This process can last from several weeks to several years. In this case, the copper becomes brownish-red. The dominant oxide is $\mathrm{Cu}_{2} \mathrm{O}$. In some cases, the film darkens, acquiring a black color characteristic of $\mathrm{CuO}$. The second stage occurs when the oxide layer reaches a certain thickness and a layer of copper salts starts forming on it. Thus, on the surface of copper oxidized in the atmospheric air, a protective layer is formed whose physical and chemical properties, different from those of the original material, are responsible for the different colors of the layer (from brown to black) with different (greenish and bluish) tints [7].

However, in our experiments, we observed a bluish white layer on the surface of copper exposed to a REP diffuse discharge. From the data available in the literature, we know only one copper compound, which could be colored white. This is tenorite, which has the formula of copper oxide $(\mathrm{CuO})$, but a different crystal lattice. As mentioned above, the interaction of a REP DD with air results in the formation of nitrogenous compounds containing NO and NH groups and compounds containing $\mathrm{OH}$ groups. When the interaction is prolonged, nitric acid $\left(\mathrm{HNO}_{3}\right)$ vapors are also formed [5]. 
It is probable that the discharge gives rise to chemical reactions resulting in the formation of copper compounds colored blue or dark blue, such as

$3 \mathrm{Cu}+8 \mathrm{HNO}_{3}=3 \mathrm{Cu}\left(\mathrm{NO}_{3}\right)_{2}+2 \mathrm{NO}+4 \mathrm{H}_{2} \mathrm{O}$.

The copper nitrate $\mathrm{Cu}\left(\mathrm{NO}_{3}\right)_{2}$ is originally white; however, in the presence of water, it becomes blue crystalline hydrate [8]. The formation of nitrogenous compounds on copper surfaces is confirmed by the appearance of green inclusions under the action of the diffuse discharge plasma (Fig. 6).

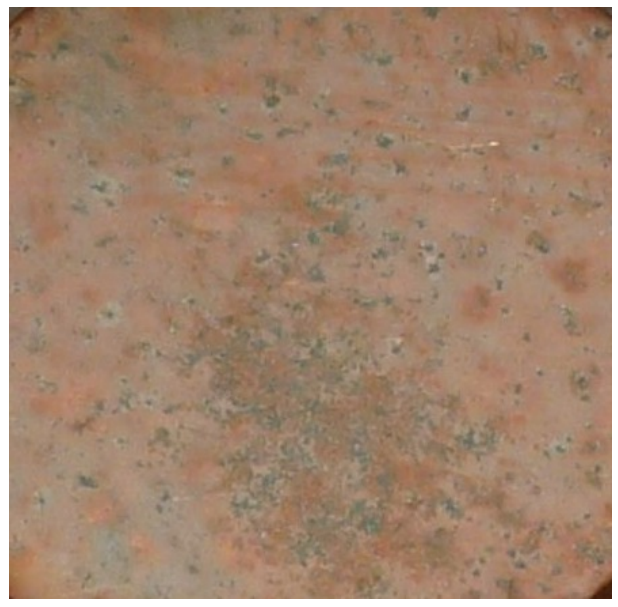

Figure 6. The surface of a copper sample exposed to 2000 discharge pulses.

In this experiment, the discharge current density was increased by decreasing the cathode tube diameter to $6 \mathrm{~mm}$ and the electrode gap spacing to $11 \mathrm{~mm}$. The sample surface was exposed to 2000 discharge pulses.

As can be seen in Fig. 3, the sample surface is riddled with green inclusions. Analysis has shown that the inclusion material is copper nitride $\left(\mathrm{Cu}_{3} \mathrm{~N}\right)$. In our conditions, the copper nitride could be formed as a result of the following reactions:

$3 \mathrm{Cu} \mathrm{O}+2 \mathrm{NH}_{3}=2 \mathrm{Cu}_{3} \mathrm{~N}+3 \mathrm{H}_{2} \mathrm{O}$,

$6 \mathrm{CuO}+4 \mathrm{NH}_{3}=2 \mathrm{Cu}_{3} \mathrm{~N}+\mathrm{N}_{2}+6 \mathrm{H}_{2} \mathrm{O}$,

and

$6 \mathrm{Cu}+2 \mathrm{NH}_{3}=2 \mathrm{Cu}_{3} \mathrm{~N}+3 \mathrm{H}_{2}[8,9]$.

Thus, it can be stated that the most effective processes occurring on a copper surface exposed to a pulsed diffuse discharge initiated by a runaway electron beam are

- removal of carbon-containing compounds and

- oxidation.

When the discharge power is high enough and the exposure is prolonged, nitrogenous compounds can be formed on the exposed surface.

\section{ACKNOWLEDGMENTS}

The work is performed in the framework of the Russian Science Foundation (Project No. 14-29-00052). 


\section{REFERENCES}

[1] Koval', N. N., Gromov, V. E., [Modern Trends in Modification of Materials Structure and Properties], NTL, Tomsk, 380 (2015).

[2] Liner, V. I., [The protective coating of metals], Metallurgy, Moscow, 558 (1974).

[3] Averyanov, E. E., [Reference anodizing], Mechanical engineering, Moscow, 224 (1988).

[4] Tarasenko, V. F., [Runaway Electrons Preionized Diffuse Discharges], Nova Science Publishers Inc., New York, 598 (2014).

[5] Rusin, A. A., Batalova, V. N., Sosnin, E. A., Shulepov, M. A., "Photochemical air ozonizer," Proc. VIII AllRussian Conference School "Innovation 2012", 1, 137-140 (2012).

[6] Shulepov, I. A., [Development and application of combined atomic and nuclear physics methods for examining modified layers of materials], $\mathrm{PhD}$ thesis, Tomsk, 141 (2004).

[7] Shemakhanskaya, M. S., [Restoration of Metals (Methodic recommendations)], VNIIR, Moscow, 108 (1989).

[8] Lidin, R. A., Molochko, V. A., Andreeva, L. L., [Reactions of Inorganic Substances: Reference Book], Drofa, Moscow, 480 (2007).

[9] Ripan, R., Chetyanu, I., [Inorganic chemistry], Mir, Moscow, 560 (1971). 